\title{
Charge Remote Fragmentation in Electron Capture and Electron Transfer Dissociation
}

\author{
Xiaojuan Li, ${ }^{a}$ Cheng Lin, ${ }^{a}$ Liang Han, ${ }^{\text {a,b }}$ Catherine E. Costello, ${ }^{a}$ \\ and Peter B. O'Connor ${ }^{\mathrm{a}, \mathrm{c}}$ \\ ${ }^{a}$ Mass Spectrometry Resource, Department of Biochemistry, Boston University School of Medicine, Boston, \\ Massachusetts, USA \\ ${ }^{b}$ Department of Chemistry, Boston University, Boston, Massachusetts, USA \\ ${ }^{c}$ Department of Chemistry, University of Warwick, Coventry, United Kingdom
}

\begin{abstract}
Secondary fragmentations of three synthetic peptides (human $\alpha$ A crystallin peptide 1-11, the deamidated form of human $\beta \mathrm{B} 2$ crystallin peptide 4-14, and amyloid $\beta$ peptide 25-35) were studied in both electron capture dissociation (ECD) and electron-transfer dissociation (ETD) mode. In ECD, in addition to $\mathrm{c}$ and $\mathrm{z}$. ion formations, charge remote fragmentations (CRF) of $\mathrm{z} \cdot$ ions were abundant, resulting in internal fragment formation or partial/entire side-chain losses from amino acids, sometimes several residues away from the backbone cleavage site, and to some extent multiple side-chain losses. The internal fragments were observed in peptides with basic residues located in the middle of the sequences, which was different from most tryptic peptides with basic residues located at the $C$-terminus. These secondary cleavages were initiated by hydrogen abstraction at the $\alpha-, \beta-$, or $\gamma$-position of the amino acid side chain. In comparison, ETD generates fewer CRF fragments than ECD. This secondary cleavage study will facilitate ECD/ETD spectra interpretation, and help de novo sequencing and database searching. (J Am Soc Mass Spectrom 2010, 21, 646-656) (c) 2010 Published by Elsevier Inc. on behalf of American Society for Mass Spectrometry
\end{abstract}

$\mathrm{R}$ adical induced gas-phase fragmentation processes in peptides/proteins have been extensively studied. Many methods have been used to generate free radicals in peptides/proteins, including homolytic cleavages of covalent bonds that couple the chemical/chromophore groups or radical initiators to the peptides, dissociation of the noncovalent complexes of peptides, and peptide ion-electron/ion-ion interaction methods. The weak covalent bonds in the lysine peroxycarbamates (LPC) and the free radical initiator Vazo 68-peptide conjugates may be collisionally activated to generate free radicals in peptide ions [1-3]. Collision induced dissociation (CID) was also used to generate radical cations from the $\mathrm{S}$ - and N-nitrosopeptides or sodiated nitrate esters of serine and homoserine derivatives $[4,5]$. Site-specific radical directed dissociations can be induced by photodissociation (PD) of a carbonsulfur $(\mathrm{C}-\mathrm{S})$ bond introduced at phosphorylated serine and threonine residues through elimination of the phosphate in basic solution followed by addition of a thiol with an attached naphthyl based chromophore group [6], or PD/CID of a carbon-iodine (C-I) bond at iodinated tyrosine, and to a lesser extent, iodinated histidine [7]. CID of the ternary complex $[\operatorname{Metal}(\mathrm{L})(\mathrm{M})]^{n+\cdot}$ that contains a metal ion such as $\mathrm{Cu}(\mathrm{II})$ or $\mathrm{Co}(\mathrm{III})$, an

Address reprint requests to Professor P. B. O'Connor, Department of Chemistry, University of Warwick, Gibbet Hill Road, Coventry, CV4 7AL, UK. E-mail: p.oconnor@warwick.ac.uk auxiliary ligand L (typically an amine), and oligopeptide $M$ has been shown to generate molecular radical cations $\left(\mathrm{M}^{+\cdot}\right)$ [8-11]. The PD-CID of the crown ether based photolabile iodonaphthyl radical precursor/ peptide complexes can also generate radicals on the side chain, and this mediates the backbone fragmentation [12]. Most of these methods require re-isolation of the radical peptide ions and further collisional activation. On the other hand, ion-electron/ion-ion interaction methods can simplify the analysis process by avoiding the prior covalent modification, formation of complexes, and/or additional isolation/reactivation steps. Multiply protonated peptides can interact directly with high-energy $(>10 \mathrm{eV})$ and low-energy $(<0.2$ $\mathrm{eV}$ ) electrons to generate radical peptide ions, as observed in electron induced dissociation (EID) [13-15] and electron capture dissociation (ECD) [16-18], respectively. Radical anions may also be used to transfer an electron to the multiply protonated peptides to induce backbone fragmentation pathways similar to those observed in ECD, as demonstrated in electron-transfer dissociation (ETD) [19-21].

In ECD, after electron capture by the multiply protonated peptide ion, the subsequent nonselective $\mathrm{N}-\mathrm{C}_{\alpha}$ bond cleavage generates an even-electron $c$ ion and a radical $z$. ion [16-18]. The radical located on the N-terminal $\alpha$-carbon of the $z$ - ions may initiate further rearrangement reactions to induce many kinds of secondary fragmentations along the peptide backbone or on the side chain. A
(C) 2010 Published by Elsevier Inc. on behalf of American Society for Mass Spectrometry. 1044-0305/10/\$32.00

doi:10.1016/j.jasms.2010.01.001
Published online January 18, 2010 Received September 15, 2009

Revised January 3, 2010 Accepted January 12, 2010 
common fragmentation channel is the $\alpha$-cleavage of the $\mathrm{C}_{\beta}-\mathrm{C}_{\gamma}$ bond of the $\mathrm{N}$-terminal residue of the $\mathrm{z}$ - ion, resulting in the formation of $\mathrm{w}$-ions. However, the radical may also migrate to other positions via hydrogen abstraction to induce bond cleavages remote from the initial radical site, similar to the dissociation pathways observed in the vacuum ultraviolet (VUV) photodissociation of peptide ions, and the surface induced dissociation (SID) and CID of peptide radical cations $[22,23]$. In ECD, the likelihood of radical rearrangement generally decreases as the distance between the primary cleavage site and the hydrogen abstraction site along the peptide backbone increases, although through-space hydrogen abstraction does occur [24, 25]. Neutral losses from the reduced precursor ions and secondary side-chain losses from $\mathrm{z}$. ions in ECD have been studied extensively in linear peptides [26-33]. Loss of the entire or partial side chain from $z$. ions was considered to be associated with the $\gamma$ - or $\alpha$-radical formation on the corresponding amino acid, respectively [28, 29]. Because these secondary fragmentations do not involve the charge directly, and the bond cleavage sites are spatially remote from the charge carrier site, they can be considered as "charge-remote fragmentations" (CRFs) [11, 34-39]. CRFs are not as common in ETD, presumably because of the less energy deposited upon electron transfer, as well as the collisional cooling effect present in the ion trap commonly used to carry out ETD experiments. However, when $z$. ions from ETD were collisionally activated, extensive radical induced fragmentations were also readily observed [40]. CRF may also lead to secondary backbone cleavages, as evident in the ECD of doubly charged cyclic peptides, where multiple backbone cleavages and side-chain losses were observed with the capture of a single electron [41]. A free radical cascade (FRC) mechanism was proposed, in which the initial $\alpha$-radical can propagate along the peptide backbone to generate another $\alpha$-radical with a stable even-electron neutral as the leaving group. FRC also predicts the formation of internal fragments in ECD of linear peptides. However, since most peptide ions studied in ECD experiments are electrospray ionization (ESI)-generated tryptic peptides with charges located near the termini, the internal fragments, even if formed, would be neutral and undetectable. Nevertheless, for non-tryptic peptides, or for tryptic peptides with basic residues(s) located in the middle of the sequence either due to missed cleavage(s) or the presence of histidine residue(s), internal fragments may be detected. To test this hypothesis, three synthetic peptides were investigated by ECD and ETD. The internal fragment ions were observed and the postulated mechanisms were discussed. Side-chain losses were also investigated to help further understand the radical's fate in $\mathrm{z}$. ions.

\section{Experimental}

Human $\alpha$ A crystallin peptide (1-11, MDVTIQHPWFK), the deamidated form of human $\beta \mathrm{B} 2$ crystallin peptide
(4-14, HETEAGKPESL) (both from Anaspec, Fremont, CA, USA), and amyloid $\beta$ peptide (25-35, GSNKGAIIGLM) (Bachem AG, Philadelphia, PA, USA) were used without further purification. All other chemicals were purchased from Sigma (St. Louis, MO, USA). The peptides were analyzed by ECD at $\sim 10^{-5} \mathrm{M}$ concentration in the spray solution containing 49.5:49.5:1 ( $\mathrm{vol} / \mathrm{vol} / \mathrm{vol})$ methanol:water:formic acid. ECD analysis was performed on a custom built ESI qQq-Fourier transform ion cyclotron resonance mass spectrometer (FT-ICR MS) equipped with an external nanospray source and a 7 Tesla actively shielded magnet as described previously $[42,43]$. In the ECD experiments, the multiply charged precursor ions were isolated in the front end quadrupole (Q1), and externally accumulated in the collision cell (Q2). These ions were then transmitted to and trapped in the cylindrical ICR cell by gated trapping. The trapped ions were irradiated with low-energy electrons $(\sim 0.2 \mathrm{eV})$, generated by an indirectly heated dispenser cathode (Heatwave, Watsonville, CA, USA). A grid, located in front of the cathode, was kept at +10 $\mathrm{V}$ to help guide the electrons into the ICR cell. The transients were zero-filled twice and Fourier transformed without apodization. All spectra were internally calibrated using the precursor and charge reduced ions.

The ETD experiments of these three peptides were also performed on an amaZon (Bruker Daltonics, Bremen, Germany) ion trap instrument equipped with an Apollo II ion source, at the concentration of $\sim 1 \mu \mathrm{M}$ in the same spray solution as used in ECD experiment. The low mass cutoff value was $m / z 100$ to 120 and the reaction time was between 100 and 120 ms. Smart decomposition was employed to improve fragmentation [44].

\section{Results and Discussion}

ECD measurements of three synthetic peptides were performed, with one mimicking a tryptic peptide and two being non-tryptic peptides. Figure 1 shows the ECD spectrum of the tryptic peptide ( $\alpha \mathrm{A}$ crystallin peptide, 1-11) with a histidine residue in the middle of the sequence. Figure 2 and Figure 3 show the ECD spectra of two non-tryptic peptides (amyloid $\beta$ peptide, 25-35 and the deamidated form of $\beta \mathrm{B} 2$ crystallin peptide, 4-14) each containing a lysine residue in the middle of the peptide sequence. In the ECD and ETD spectra of this study, peaks corresponding to both the chargereduced molecular ions and its hydrogen loss products $\left([\mathrm{M}+\mathrm{nH}]^{(\mathrm{n}-1)+\cdot}\right.$ and $\left.[\mathrm{M}+(\mathrm{n}-1) \mathrm{H}]^{(\mathrm{n}-1)+}\right)$ were observed. These spectra were dominated by $\mathrm{c}$ and $\mathrm{z} \cdot$ ion series, as expected. There were also several $b$ ions present in the spectra, particularly in Figure 2, in agreement with previous studies $[45,46]$. In addition, peaks corresponding to entire and partial side-chain losses from $\mathrm{z}$ - ions, as well as internal fragments were observed. In comparison, fewer CRF fragments were observed in the ETD spectra of the deamidated form of 


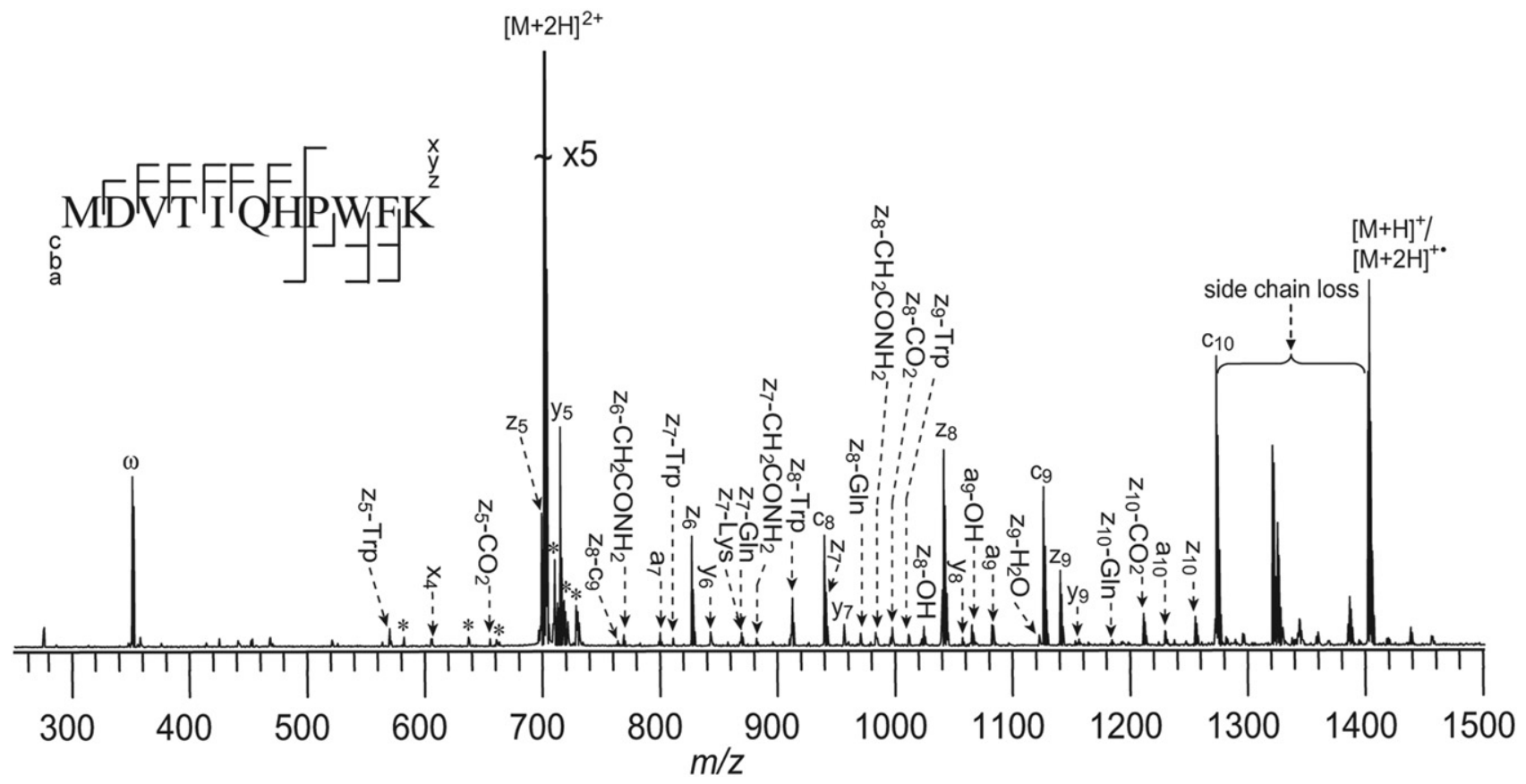

Figure 1. ECD spectrum of $\alpha \mathrm{A}$ crystallin peptide (1-11). * Represents the electronic noise peak or salt adducts, $\omega$ represents the harmonic peaks. Peaks marked with "-amino acid residue" represent the entire side-chain losses, and the partial side-chain losses are represented by the molecular formulas of the departing group(s). Side-chain loss means loss from the charge-reduced molecular ions. The cleavage pattern is shown as the inset.

$\beta \mathrm{B} 2$ crystallin peptide, 4-14 (Figure 4) than in its ECD spectrum (Figure 3). Complete peak lists and assignments are available in Supplementary Tables 1-5, which can be found in the electronic version of this article. ETD spectra of the doubly charged $\alpha$ A crystallin peptide and amyloid $\beta$ peptide are shown in Supplementary Figures S1 and S2, respectively.
Entire Side-Chain Loss from z. Ions Associated with $\gamma$-Radical Formation on the Side Chain

For amino acids containing $\gamma$-hydrogen(s) on their side chains, entire side-chain losses from $z$ - ions may be observed, usually at sites remote from the primary backbone cleavage sites $[11,12,23,28]$. These amino

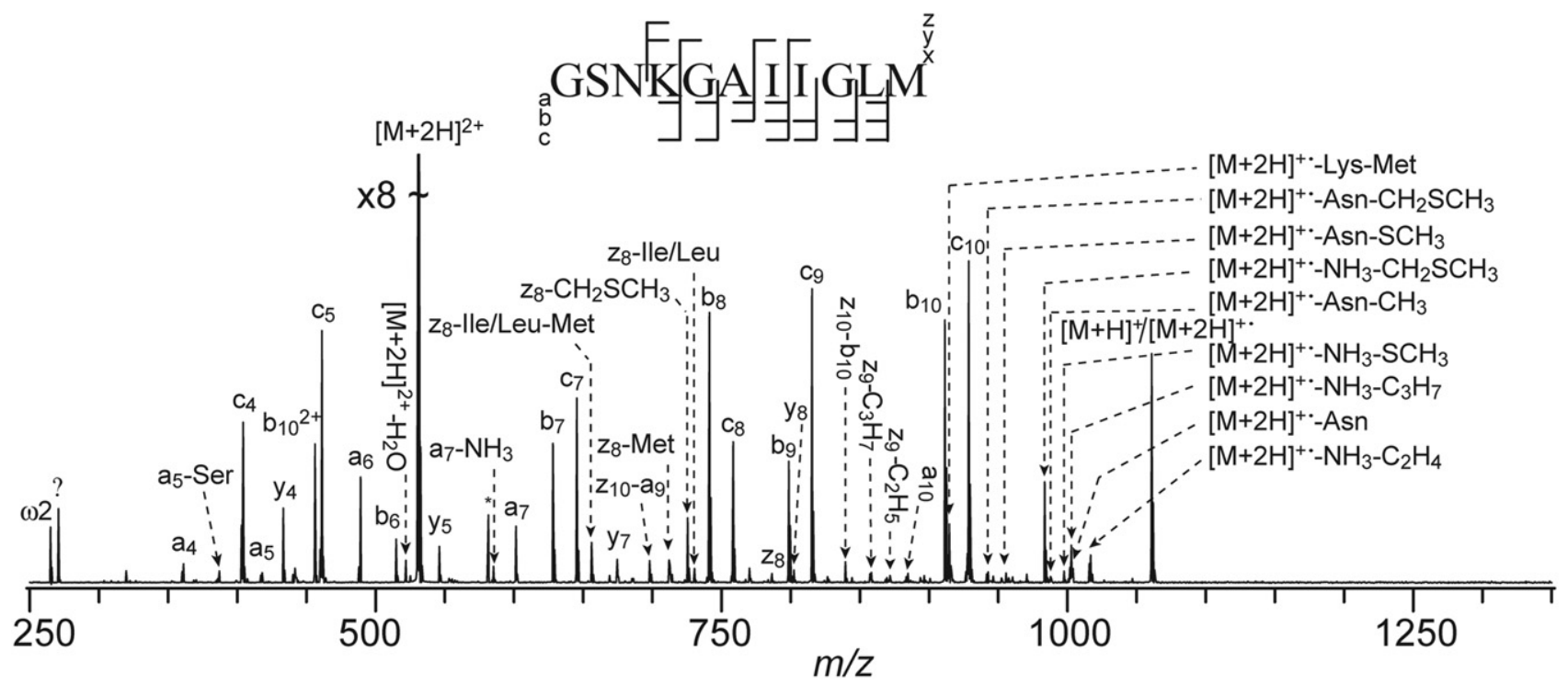

Figure 2. ECD spectrum of amyloid $\beta$ peptide (25-35). Peak labeling follows the same convention as in Figure 1 . The cleavage pattern is shown as the inset. (Reprinted with permission from reference [47].) 


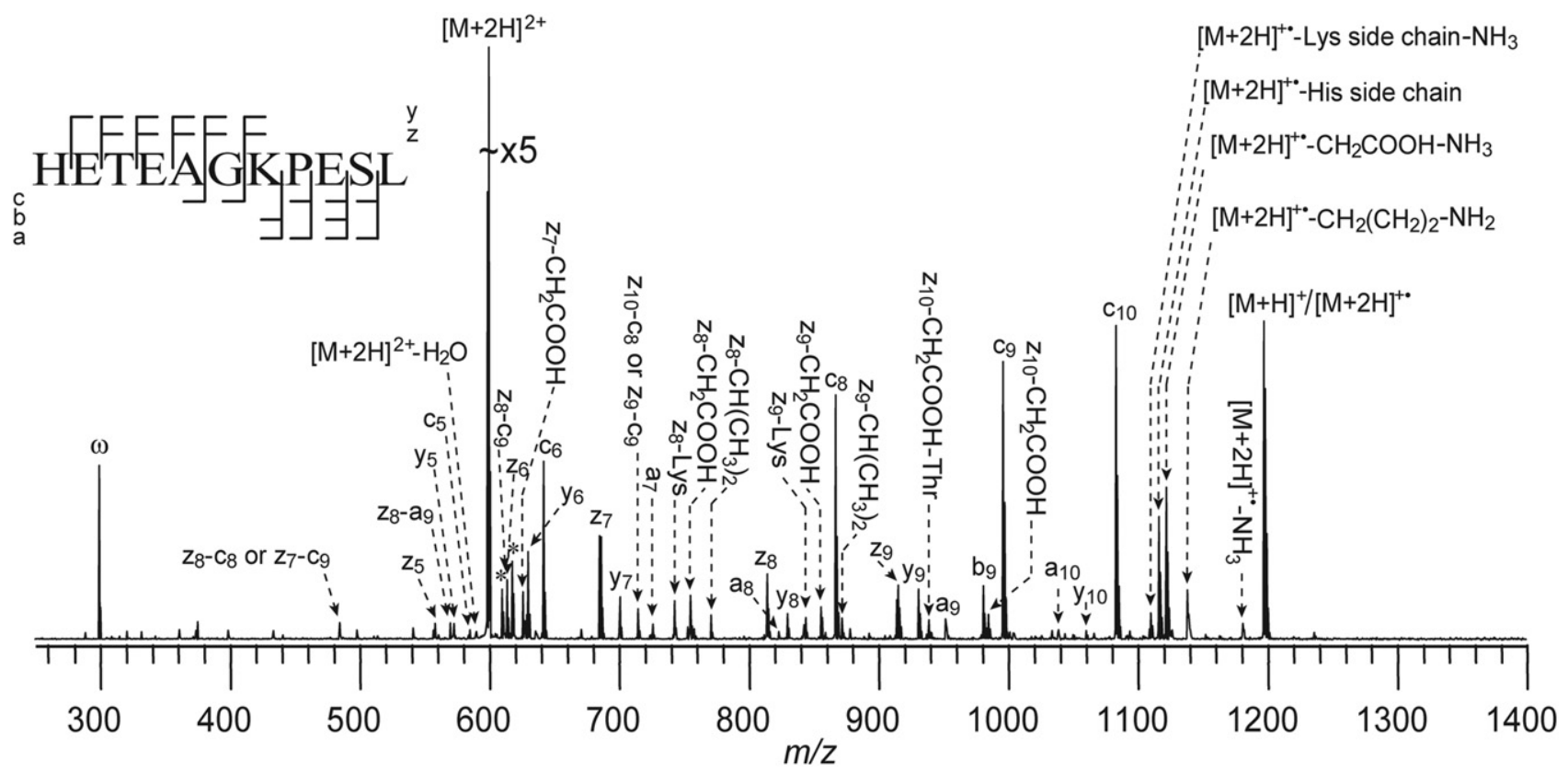

Figure 3. ECD spectrum of the deamidated form of $\beta B 2$ crystallin peptide (4-14). Peak labeling follows the same convention as in Figure 1. The cleavage pattern is shown as the inset.

acids include: Ile/Leu, Lys, Arg, Glu, Gln, Cys, Met, and Val. Scheme 1 illustrates a possible mechanism for the loss of the entire side chain, using glutamine as an example. After the initial $\mathrm{z}$. fragment formation, the $\alpha$-radical on the $\mathrm{N}$-terminal carbon of the $\mathrm{z} \cdot$ fragment may abstract one hydrogen from the $\gamma$-carbon of the glutamine side chain, and the newly formed $\gamma$-radical can undergo an $\alpha$-cleavage reaction and release the side chain as an even-electron, neutral species from the peptide, leaving the radical on the peptide backbone. For example, in the ECD spectrum of the $\alpha$ A crystallin peptide (1-11), the entire glutamine side chain was lost from the $z_{7} \cdot$ and $z_{8} \cdot$ ions, and the lysine side chain was lost from the $z_{7}$. ions (Figure 1); in none of these cases is the backbone cleavage site adjacent to the site of side-chain loss. In other ECD spectra, glutamic acid side-chain losses from $z$. fragments were also detected with low abundance (data not shown). In the ECD spectrum of amyloid $\beta$ peptide (25-35), peaks corresponding to entire side-chain losses from $\mathrm{z}$. fragments of leucine/isoleucine, or methionine were also observed (Figure 2) [47].

In the ECD spectrum of the $\alpha \mathrm{A}$ crystallin peptide (1-11) (Figure 1), a series of peaks corresponding to loss of the entire side chain of a tryptophan residue (129 Da) from the $z$ - fragments were observed, some of which have relatively high abundance, such as the $z_{8}-\operatorname{Trp}$ at $\mathrm{m} / \mathrm{z}$ 911. For all of these $\mathrm{z} \cdot \mathrm{Trp}$ ions, the backbone cleavage sites were remote from the tryptophan residue. This remote loss of tryptophan side chain from $z$. ions has been reported previously in ECD and ETD studies, the latter requiring additional collisional activation $[28,40]$. Siu and coworkers have observed the 129 Da loss of the tryptophan side chain in the CID mass spectra of the $\mathrm{M}^{+\cdot}$ ion of WGG formed by the collisional induced dissociation of the $\left[\mathrm{Cu}^{\text {II }}(\text { dien }) \mathrm{M}\right]^{2+}$. complex [9], where they proposed that the tryptophan side chain was lost as a carbene species, following the 1,4-proton transfer that puts the charge on the backbone carbonyl and the radical on the $\beta$-carbon. Although there is no $\gamma$-hydrogen in the common canonical representation of the tryptophan structure as previously suggested [23, 28], a tautomeric form of tryptophan does contain a $\gamma$-hydrogen, which can be used to explain the abundant tryptophan side-chain losses present here, as illustrated in Scheme 2 . This postulated mechanism may also account for the side-chain loss from tyrosine residue (106 Da), as seen in both ECD of protonated peptide ions [28] and CID of peptide radical ions [8]. Phenylalanine does not have a hydroxyl group to generate the tautomeric structure like tyrosine, and loss of the entire phenylalanine side chain from $z$. ions has seldom been observed, except once as reported, but under unusual conditions [48]. The histidine residue can assume a $\gamma$-hydrogen containing tautomeric form as well, which may lead to a complete side-chain loss of $\sim 80 \mathrm{Da}$, although it has not been observed in ECD to date. Nonetheless, histidine side-chain loss has been reported in the dissociation of the hydrogen deficient peptide radicals [12], as well as in the CID and SID spectra of $\mathrm{M}^{+\cdot}$ ions [11]. This potential $\sim 80 \mathrm{Da}$ loss is different from the $\sim 82$ Da loss from the charge reduced species reported in previous studies [26, 32]. The $\sim 82$ Da loss proceeds via a different mechanism, where the charge neutralization at the protonated imine nitrogen site generates a stable carbon radical to induce loss of the entire side chain. It is important to note that these neutral side-chain losses are different from the cationic 


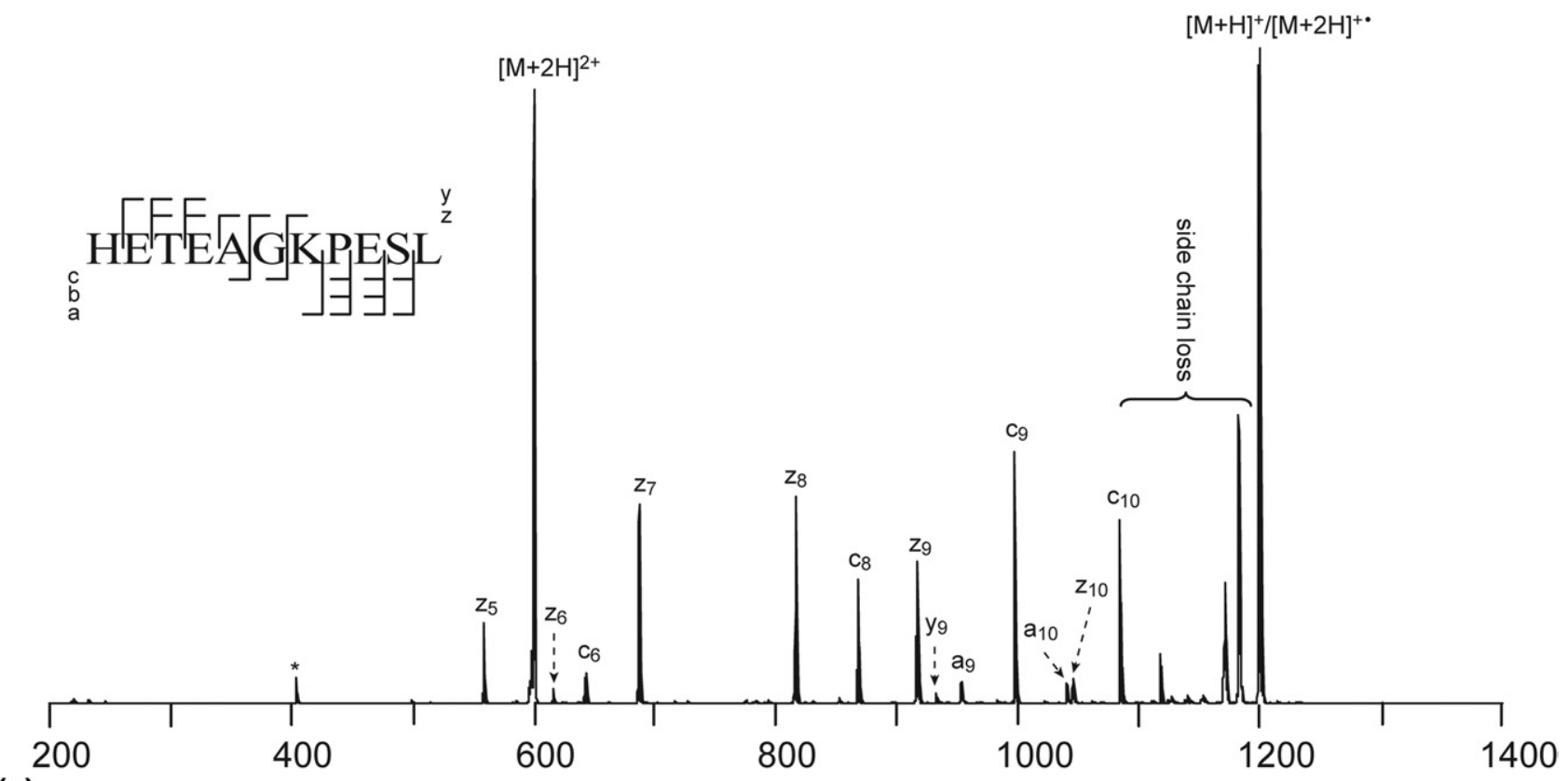

(a)

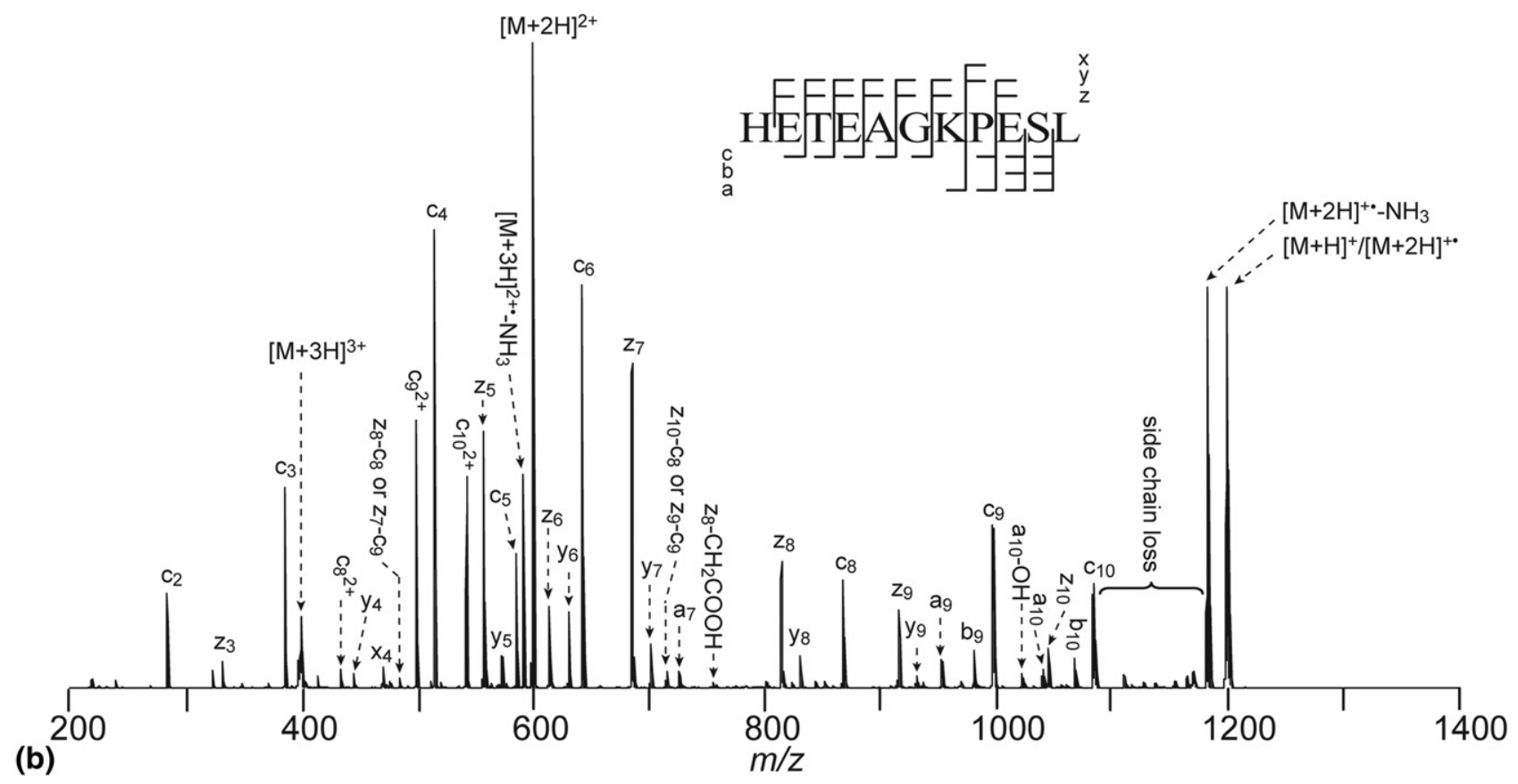

Figure 4. ETD spectra of the deamidated form of $\beta$ B2 crystallin peptide (4-14) generated from 2+ charge state $(\mathbf{a})$ and $3+$ charge state $(\mathbf{b}) .{ }^{*}$ Represents two fluoranthene molecules. Side-chain loss means loss from the charge-reduced molecular ions. Cleavage patterns are shown as the insets.

side-chain losses in the EID spectra of protonated aromatic amino acid or peptides containing aromatic moieties, where the electron ejected by EI is typically from the aromatic ring itself, leaving both the charge and the radical on the aromatic ring. This radical cation may rearrange to lose a cationic species, which is $1 \mathrm{Da}$ higher than that of the neutral loss (tryptophan: $130 \mathrm{Da}$, phenylalanine: $91 \mathrm{Da}$, tyrosine: $107 \mathrm{Da}$, and histidine: 81 Da) [14].
Multiple side-chain losses from $z$ - ions were also observed in ECD spectra. For example, in the ECD spectrum of the amyloid $\beta$ peptide (25-35), peaks corresponding to the losses of Ile/Leu and Met side chains from the $z_{8}$. fragment were observed $\left(z_{8}-\right.$ Ile/Leu-Met) (Figure 2). This is expected, as loss of the entire side chain leaves the radical on the backbone, which may induce further fragmentations. As long as the radical still remains on the backbone, the side-chain loss cascade may continue. 


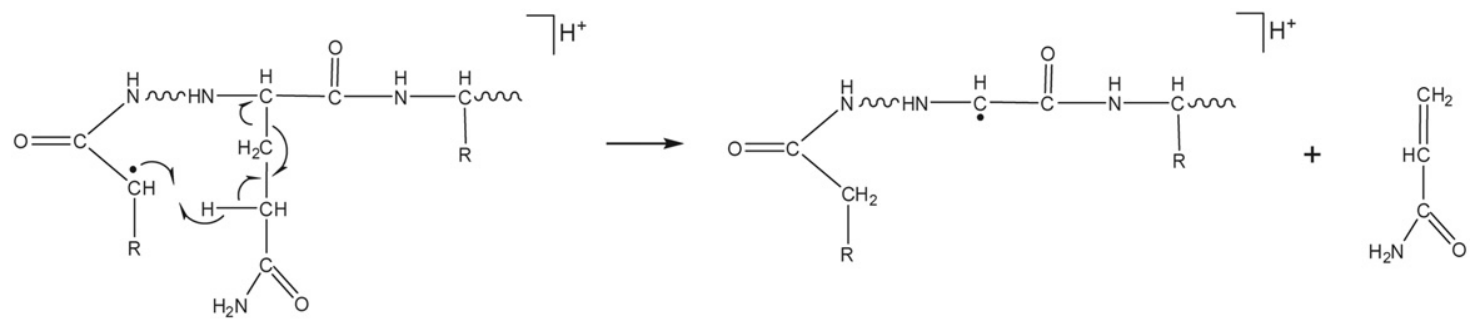

Scheme 1. Entire side-chain loss from $\mathrm{z}$ - ions via gamma hydrogen abstraction.

\section{Partial Side-Chain Loss from z. Ions Associated with $\alpha$-Radical Formation on the Side Chain}

Furthermore, in Figure 1, there were a series of peaks corresponding to the partial side-chain losses of glutamine residue $\left(\mathrm{C}_{2} \mathrm{H}_{4} \mathrm{NO}\right)$ from $\mathrm{z} \cdot$ ions, with the glutamine residue located either directly at the backbone cleavage site or several amino acids away from it. In this peptide, the $\mathrm{z}_{6} \cdot \mathrm{C}_{2} \mathrm{H}_{4} \mathrm{NO}$ fragment was assigned as the $\mathrm{w}_{6}$ ion resulting from the direct cleavage of the $\mathrm{C}_{\beta}-\mathrm{C}_{\gamma}$ bond adjacent to the initial radical site, because the side-chain loss occurred at only glutamine residue in the sequence. The other partial side-chain losses of glutamine from $z$. ions had to be formed via throughspace radical rearrangement. The detailed mechanisms for the partial glutamine side-chain losses from $\mathrm{z}$ - ions are shown in Scheme 3, similar to those proposed by other groups [12, 23, 28, 41]. The $\alpha$-carbon radical, either in the original position or as a result of the $\alpha$-hydrogen abstraction will initiate an $\alpha$-cleavage reaction to break the bond between the $\beta$ - and $\gamma$-carbons of the side chain. This will induce the partial loss of the side chain while the radical remains on the lost neutral species, and an even-electron species is formed for the remaining $\mathrm{z}$ fragment. Thus, the $\alpha$-radical, $\mathrm{N}$ - terminal to the $\mathrm{z}$ - fragment may induce the partial side-chain losses in ECD via through-bond ( $\mathrm{w}$ ion formation, Scheme 3a) or through-space (Scheme $3 \mathbf{b}$ ) mechanisms. The remaining $\mathrm{z}$ fragments contain no radicals to initiate further reaction.

A series of partial glutamic acid side-chain losses $\left(\mathrm{C}_{2} \mathrm{H}_{3} \mathrm{O}_{2}\right)$ from the corresponding $\mathrm{z}$. ions were observed in the ECD spectrum of the deamidated form of the $\beta B 2$ crystallin peptide (4-14) as well (Figure 3). For this peptide, some of the side-chain loss fragment ions contain multiple glutamic acid residues located either directly at, or remote from, the backbone cleavage sites. The $\mathrm{z}_{8} \cdot-\mathrm{C}_{2} \mathrm{H}_{3} \mathrm{O}_{2}$ and $\mathrm{z}_{10} \cdot-\mathrm{C}_{2} \mathrm{H}_{3} \mathrm{O}_{2}$ ions may be generated either as the $\mathrm{w}$ ions or formed following radical migration, while the other $\mathrm{z} \cdot-\mathrm{C}_{2} \mathrm{H}_{3} \mathrm{O}_{2}$ ions had to be formed after through-space hydrogen abstraction. The highfrequency of the partial side-chain losses of $z$. ions indicates that, after the formation of $\mathrm{z}$. ions in ECD, the radical on the $z$ ions will have ample time to migrate and induce further cleavages, without the need of additional activation. These secondary fragmentations usually do not depend on the charge location in the peptides. Thus, the CRF may be a common pathway for partial side-chain losses from $z$. ions, especially in

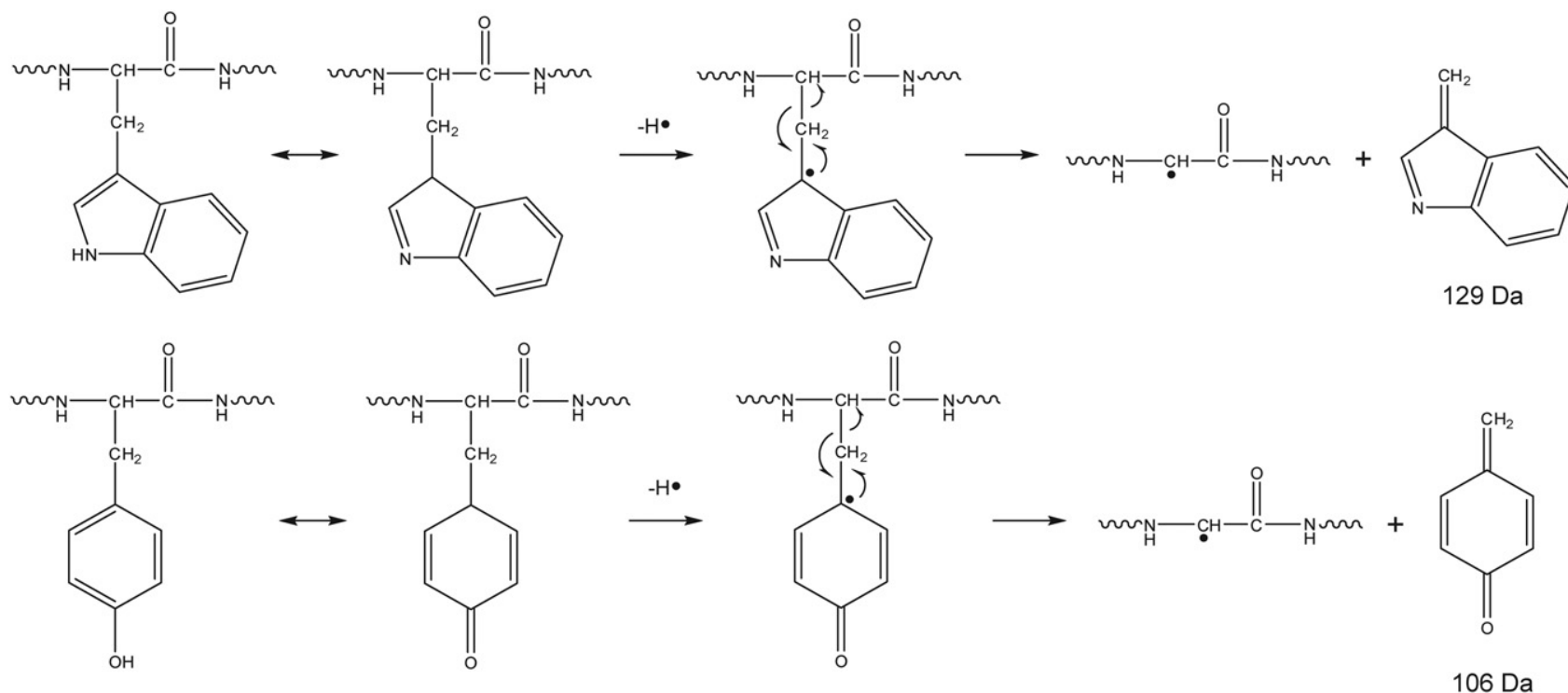

Scheme 2. Entire side-chain loss from $z$. ions via $\gamma$ hydrogen abstraction involving aromatic amino acids. 
(a)
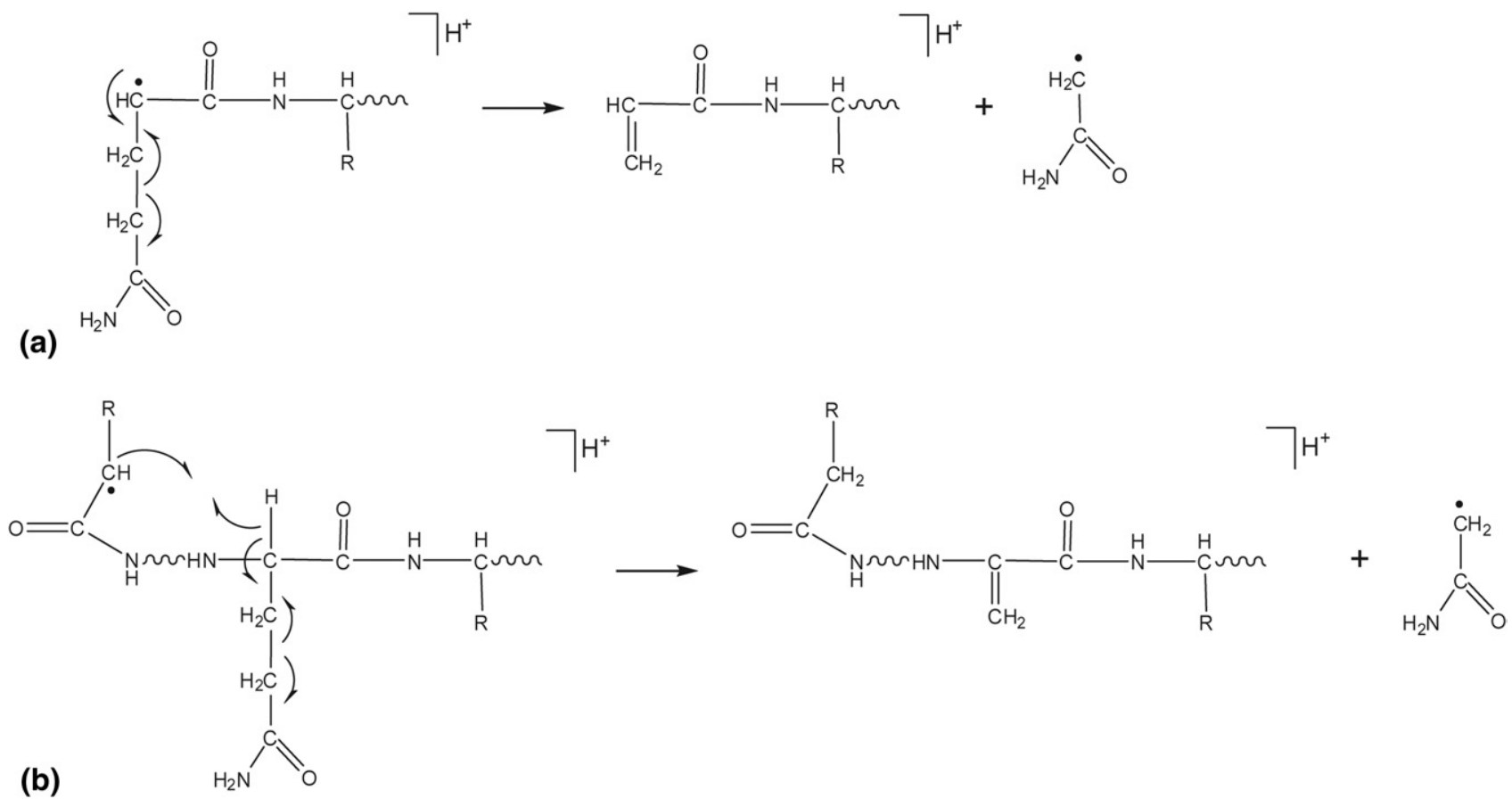

Scheme 3. Partial side-chain loss from $z$. ions via $\alpha$ hydrogen abstraction [through-bond, (a) and through-space, (b)].

tryptic peptides, which usually have a charge carrier at the C-terminus that permits the detection of secondary C-terminal fragments.

This phenomenon has important implications in de novo sequencing. A specific side-chain loss from $z$. ions does not warrant the assignment of that amino acid at the cleavage site because the loss may occur at remote sites. For example, in the differentiation of Leu/Ile, it is not sufficient to identify Leu/Ile solely based on the mass difference between the $\mathrm{w}$ - and the corresponding $\mathrm{z}$ - ions because the partial side-chain loss of Leu/Ile may not come from the $\mathrm{N}$-terminus of the $\mathrm{z}$ - ions at all $[27,49]$. In the ECD spectrum of the amyloid $\beta$ peptide (25-35) (Figure 2), partial side-chain losses of leucine and isoleucine $\left(\mathrm{C}_{3} \mathrm{H}_{7}\right.$ and $\left.\mathrm{C}_{2} \mathrm{H}_{5}\right)$ from $\mathrm{z}_{9}$. fragment were observed to occur several residues away from the backbone cleavage site. In addition, for the partial side-chain losses of the leucine residue from $\mathrm{z}$. ions in the ECD spectrum of the deamidated form of $\beta B 2$ crystallin peptide (4-14) (Figure 3), the backbone cleavage sites were seven or eight residues away from the C-terminal leucine. Thus, it is important to assign the residue as a Xle (meaning either Leu/Ile) based on the mass difference between adjacent backbone fragment ions before looking at the side-chain loss peak for differentiation of Leu and Ile residues, and if several different Leu/Ile residues exist on the same peptide, the assignments may be ambiguous. In addition to Ile/Leu isomer differentiation, ECD can also be used to distinguish aspartic acid (Asp) and isoaspartic acid (isoAsp) based primarily on the presence of diagnostic $c+57$ and $z \cdot-57$ ions for isoAsp containing peptides [50-54].
The Asp/isoAsp result is likely to be less affected by secondary side-chain cleavages as it results from the primary backbone cleavage of the $C_{\alpha}-C_{\beta}$ bond, but for cases where several Asp/isoAsp residues are available in the same peptide, similar ambiguity to the Leu/Ile question discussed above could arise.

It has been suggested that $\alpha$-hydrogen abstraction proceeds via a stepwise mechanism [29]. However, in the current study, partial side-chain loss of methionine residue $\left(\mathrm{C}_{2} \mathrm{H}_{5} \mathrm{~S}\right)$ from the $\mathrm{z}_{8}$. ions was observed abundantly (Figure 2) with the methionine residue located at the C-terminus of the amyloid $\beta$ peptide (25-35), which was seven residues away from the backbone cleavage site. This suggests that $\alpha$-hydrogen abstraction may also proceed through space in a single step and that the abundance of the CRF fragments is influenced by both the spatial proximity and the sequence proximity of the amino acid side chain to the backbone cleavage site. Similar through-space hydrogen transfer may also occur in $\gamma$-hydrogen abstraction leading to the entire side-chain losses from residues distant from the original radical site. This hypothesis is supported by the presence of a strong peak corresponding to the $\mathrm{z}_{8} \cdot-\operatorname{Trp}$ ion (Figure 1), which is not only much more abundant than the smaller $z_{n} \cdot-\operatorname{Trp}(n=5-7)$ ions despite the comparable intensity of the related $\mathrm{z}$. ions, but also has an intensity higher than that of any other side-chain losses from $\mathrm{z}_{8}$. ions, even though the threonine and the glutamine residues are both closer to the backbone cleavage site than the tryptophan residue. Of course, one has to take into account the reactivity of the originally formed $\alpha$ radical and the stability of the 
radical in its new position, which can also affect the abundance of the side-chain losses. Nevertheless, the abundant distant side-chain losses observed in the present study underscore the importance of gas-phase peptide ion conformations in secondary fragment ion formations in ECD.

In addition, it was found that the $\mathrm{w}$-ions are not always more abundant than the same side-chain losses in longer fragment ions. For example, in Figure 1, the most abundant partial Gln side-chain loss was from the $z_{8}$. ion, rather than the $z_{6} \cdot$ ion, the latter of which produced $\mathrm{w}_{6}$. This is in contrast with the observation in a previous study [28], where the intensity of $\mathrm{w}_{5}$ ions was found to be consistently at least twice as high as those resulting from the same side-chain loss from larger $z_{n}$. ions, where $n \geq 6$. In the previous study, ECD was applied to synthetic peptides with mostly glycine residues, which can only induce limited side-chain interactions. In more complicated peptides as those studied here, gas-phase conformations will influence the secondary fragment ion abundances, even to the extent that could invalidate the criterion for differentiating $\mathrm{w}$ ions from $\mathrm{u}$ ions as proposed in earlier studies $[28,55]$.

\section{Internal Fragments Associated with $\beta$-Radical Formation on the Side Chain from $z$. Ions}

Four peaks corresponding to internal fragments were found in the ECD spectrum of the deamidated $\beta B 2$ crystallin peptide (4-14) (Figure 3). Three of them, $z_{8}-c_{8} / z_{7}-c_{9}, z_{8}-c_{9}, z_{10}-c_{8} / z_{9}-c_{9}$ are even-electron species, and one $\left(z_{8}-a_{9} \cdot\right)$ contains a radical. The internal fragments discussed in this study were labeled by the ion types at both ends, with each named after the backbone fragment ion that would have been generated, had the other end been the uncleaved C- or N-terminus of the peptide. The $\mathrm{N}$-terminal ends of all these internal fragments result from $\mathrm{N}-\mathrm{C}_{\alpha}$ bond cleavage, while the $\mathrm{C}$-terminal ends mimic either a c- or an a-type fragment ion. This suggests that the internal fragment was generated from a $\mathrm{z}$. ion with its radical initiating the secondary cleavage on the peptide backbone. Scheme 4 illustrates the postulated mechanisms for the internal fragment formation. The $\mathrm{z} \cdot$ radical can abstract a hydrogen atom from the $\beta$-carbon of the amino acid side chain to generate a $\beta$-radical, which can then induce $\alpha$-cleavage to generate the secondary cleavage on the peptide backbone. If the $\alpha$-cleavage occurs toward the C-terminal side of the $\beta$-radical, it will generate a $\mathrm{z}$-a type internal fragment ion (Scheme 4a). However, the resulting internal fragment would be an even-electron species, which is inconsistent with the experimental observation. The $\alpha$-cleavage may also proceed toward the $N$-terminal side of the $\beta$-radical, which will generate a z-c. type internal ion (Scheme $4 \mathbf{b}$ ). After the secondary backbone cleavage, the radical on the $\mathrm{NH}$ - group is not stable, and it can abstract a hydrogen via the intra- or inter-molecular hydrogen transfer to become an evenelectron species (pathway I in Scheme $4 b$ ). According to the literature, histidine and glutamine residues in c ions are $\operatorname{good} \mathrm{H}$. donors for $\mathrm{H}$ - transfer to $\mathrm{z}$. ions [56]. In this deamidated $\beta \mathrm{B} 2$ crystallin peptide (4-14), the histidine residue is located at the $\mathrm{N}$-terminus, which could be an

(a)
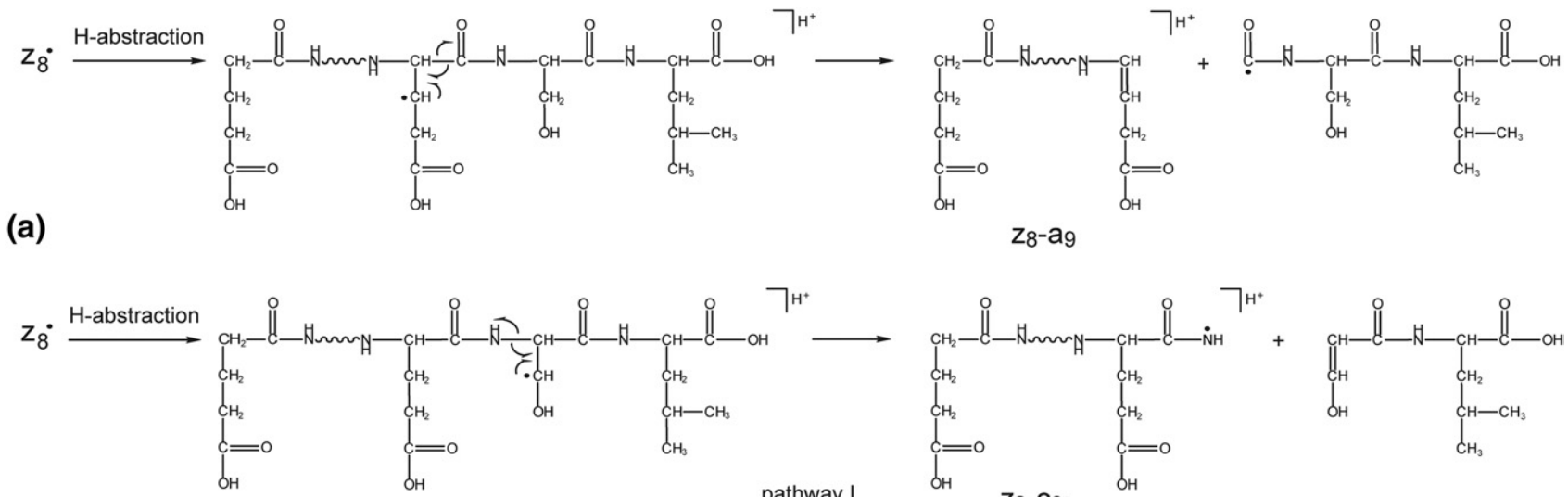

(b)
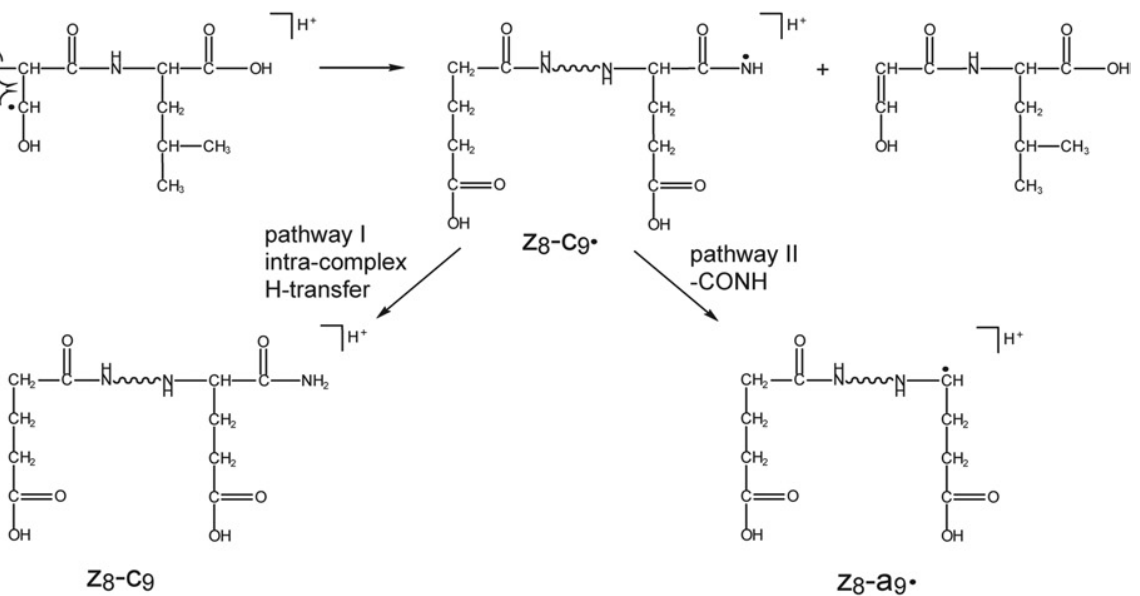

Scheme 4. Postulated mechanisms for the formation of internal fragments z8-a9 (a), z8-a9., and z8-c9

(b) via $\beta$ hydrogen abstraction in ECD of the $\beta$ B2 crystallin peptide (4-14). 
active $\mathrm{H}$ - donor. The unstable $\mathrm{N}$-radical may also lose an $\mathrm{O}=\mathrm{C}=\mathrm{NH}$ molecule to generate a radical $\mathrm{z}$-a. type internal fragment, such as the $z_{8}-a_{9}$. ion observed here (pathway II in Scheme 4b).

In the ECD spectrum of the $\alpha \mathrm{A}$ crystallin peptide (1-11) (Figure 1), one internal fragment $z_{8}-c_{9}$ was also observed with double $\mathrm{H}$. losses, which is promoted when a threonine residue is located C-terminal to the backbone cleavage site [56]. In addition, there were two internal fragments, $z_{10}-a_{9}$ and $z_{10}-b_{10}$, in the ECD spectrum of amyloid $\beta$ peptide (25-35) (Figure 2). The internal fragment $\mathrm{z}_{10}-\mathrm{a}_{9}$ also had double $\mathrm{H}$. loss because of a serine residue located $\mathrm{C}$-terminal to the backbone cleavage site. Radical induced b/y cleavage has also been discussed in the literature, where a mechanism involving the McLafferty rearrangement was proposed to explain the unusual radical y ions observed in the CID spectra of ETD generated z . ions [40]. Similar mechanism cannot be invoked here, however, as the $z_{10}-b_{10}$ ion is a normal even electron species. Most likely, it was formed from the internal fragment $z_{10}-C_{10}$ with the loss of $\mathrm{NH}_{3}$. Internal fragments in the ECD spectra of other peptides were also observed (data not shown), such as the $\beta B 2$ crystallin peptide (4-14) in its native form. All these peptides contain basic residue(s) located in the middle of the sequences, rendering the internal fragments detectable.

The abundances of internal fragments are generally lower than the normal $\mathrm{c} / \mathrm{z}$ fragments and side-chain losses from $\mathrm{z}$. ions, possibly due to the higher $\mathrm{C}_{\beta}-\mathrm{H}$ bond dissociation energy (BDE) [12]. As reported, almost all of the amino acids have lower $\mathrm{C}_{\alpha}-\mathrm{H}$ BDE than $\mathrm{C}_{\beta}-\mathrm{H}$ BDE [12]. Thus, it is easier to generate an $\alpha$-radical to induce double-bond formation between the $\alpha$ - and $\beta$-carbon of the side chain and the accompanying radical partial side-chain loss, as shown in Scheme 3. In addition, there also exist other radical stabilization pathways, such as intra-complex hydrogen transfer [56, 57], which can further reduce the possibilities of $\beta$ hydrogen abstraction, and hence the abundances of internal ions. The internal fragments observed here provide strong supports for the free radical cascade mechanism, although their low abundances also indicate a minor role FRC may play in the formation of $\mathrm{c}$ and $\mathrm{z}$. ions. Finally, like in the case of side-chain losses, both the radical stability and the peptide conformation could play important roles in the internal fragment formation.

Because ECD and ETD appear to have similar fragmentation mechanisms, the CRF was also studied in ETD. Figure 4a shows the ETD spectrum of the doubly charged deamidated $\beta$ B2 crystallin peptide (4-14). No partial/entire side-chain losses from $\mathrm{z}$. ions were present in this spectrum, and the only internal fragment $\left(\mathrm{z}_{10}-\mathrm{C}_{8} / \mathrm{z}_{9}-\mathrm{C}_{9}\right)$ observed is of very low abundance and not labeled in the spectrum. The dramatically reduced CRF fragmentations in ETD is likely due to the smaller energy deposits in ETD than that in ECD, with the difference being the ionization potential of the anion radical. Collisional cooling in the low vacuum ion-trap instrument may also contribute to the stabilization of the radicals in $\mathrm{z}$. ions and the decrease in the abundance of fragment ions formed via CRF. The ETD spectrum of the triply charged deamidated $\beta \mathrm{B} 2$ crystallin peptide (Figure $4 \mathrm{~b}$ ) showed slightly more CRFs than the doubly charged one. However, the few peaks corresponding to partial side-chain losses from $\mathrm{z}$ - ions were still of much lower intensity compared to those in the ECD spectrum of this peptide (Figure 3). In addition, two low abundance internal fragments, $\mathrm{z}_{8}-\mathrm{c}_{8} / \mathrm{z}_{7}-\mathrm{c}_{9}$ and $\mathrm{z}_{10}-\mathrm{c}_{8} / \mathrm{z}_{9}-\mathrm{c}_{9}$, were observed and are labeled, and another internal fragment $z_{8}-a_{9}$ had very low abundance and thus is not labeled. Although the internal fragment $z_{8}-C_{9}$ and the $z_{6}$. ion produced by ECD can be easily distinguished based on their accurate masses measured by the FT-ICR mass analyzer, such differentiation is impossible in ETD performed in a low-resolution ion trap (Figure $4 b$ ). It is also unclear whether the internal fragments in the ETD of the triply charged $\beta B 2$ crystallin peptide (4-14) were produced via CRF mechanism, or were generated from double electron captures, as the doubly reduced precursor ion is readily observed in this ETD spectrum. ETD of the doubly charged $\alpha \mathrm{A}$ crystallin peptide (1-11) and amyloid $\beta$ peptide (25-35) were also performed, and they both showed significantly reduced secondary fragmentations (Supplementary Figures 1 and 2, respectively). This reduced CRF fragmentation in ETD could be beneficial, as it will make database searching and/or de novo sequencing a less complex task. On the other hand, ECD's ability to generate $\mathrm{w}$ ions and other secondary fragments makes it a valuable tool for isomer differentiation, which may otherwise be difficult when using ETD alone.

\section{Conclusion}

Two non-tryptic peptides and one tryptic peptide with histidine in the middle were used as model peptides to study the secondary fragmentation in ECD/ETD. Radical rearrangement of $\mathrm{z}$ - ions may proceed through three possible pathways: $\alpha$-radical formation along the backbone can induce partial side-chain losses from $z$. ions; $\beta$-radical formation in the side chain may produce internal fragments; $\gamma$-radical formation in the side chain will generate entire side-chain losses from $z$ : ions, and this may induce further radical rearrangement, leading to multiple side-chain losses. All three secondary fragmentations took place at sites remote from the charge sites. Fewer CRF fragments were observed in ETD than in ECD. Entire and/or partial side-chain losses from z. ions in ECD can provide additional information for isomer differentiation, help with de novo sequencing, and increase the confidence of database searching. Although in general they can not be used to identify the location of certain amino acids, they do indicate the existence of specific amino acids. The current study also indicates that the low occurrence of internal fragments in peptide ECD/ETD spectra is likely due to several 
reasons: lack of charge carriers in the middle of the sequence of the commonly studied tryptic peptides; the relatively higher $\mathrm{C}_{\beta}-\mathrm{H}$ BDE than the $\mathrm{C}_{\alpha}-\mathrm{H}$ BDE, as a $\beta$-radical is needed to initiate the secondary backbone cleavage; and the low stability of the radical intermediates involved. Understanding the secondary fragmentation of $\mathrm{z}$. ions is important for the interpretation of ECD spectra with high confidence and accuracy because in some peptide ECD spectra, many major peaks are generated from entire/partial side-chain losses of $z$. ions. The existence of these CRFs may aid the peptide identification, but could also complicate database searching.

\section{Acknowledgments}

The authors gratefully acknowledge financial support from the NIH/NCRR P41RR10888, NIH/NHLBI N01HV28178, NIH/ NIGMS R01GM078293, MDS SCIEX, the ACS Petroleum Research Fund, and the loan of the amaZon instrument from Bruker Daltonics.

\section{Appendix A Supplementary Material}

Supplementary material associated with this article may be found in the online version at doi:10.1016/ j.jasms.2010.01.001.

\section{References}

1. Masterson, D. S.; Yin, H. Y.; Chacon, A.; Hachey, D. L.; Norris, J. L.; Porter, N. A. Lysine Peroxycarbamates: Free Radical-Promoted Peptide Cleavage. J. Am. Chem. Soc. 2004, 126, 720-721.

2. Yin, H.; Chacon, A.; Porter, N. A.; Yin, H. Y.; Masterson, D. S. Free Radical-Induced Site-Specific Peptide Cleavage in the Gas Phase: LowEnergy Collision-Induced Dissociation in ESI- and MALDI Mass Spectrometry. J. Am. Soc. Mass Spectrom. 2007, 18, 807-816.

3. Hodyss, R.; Cox, H. A.; Beauchamp, J. L. Bioconjugates for Tunable Peptide Fragmentation: Free Radical Initiated Peptide Sequencing (FRIPS). J. Am. Chem. Soc. 2005, 127, 12436-12437.

4. Hao, G.; Gross, S. S. Electrospray Tandem Mass Spectrometry Analysis of S- and N-Nitrosopeptides: Facile Loss of NO and Radical-Induced Fragmentation. J. Am. Soc. Mass Spectrom. 2006, 17, 1725-1730.

5. Wee, S.; Mortimer, A.; Moran, D.; Wright, A.; Barlow, C. K.; O'Hair, R. A. J.; Radom, L.; Easton, C. J. Gas-Phase Regiocontrolled Generation of Charged Amino Acid and Peptide Radicals. Chem. Commun. 2006, (40), 4233-4235.

6. Diedrich, J. K.; Julian, R. R. Site-Specific Radical Directed Dissociation of Peptides at Phosphorylated Residues. J. Am. Chem. Soc. 2008, 130, 12212-12213.

7. Ly, T.; Julian, R. R. Residue-Specific Radical-Directed Dissociation of Whole Proteins in the Gas Phase. J. Am. Chem. Soc. 2008, 130, 351-358.

8. Chu, I. K.; Rodriquez, C. F.; Lau, T. C.; Hopkinson, A. C.; Siu, K. W. M. Molecular Radical Cations of Oligopeptides. J. Phys. Chem. B 2000, 104, 3393-3397.

9. Bagheri-Majdi, E.; Ke, Y. Y.; Orlova, G.; Chu, I. K.; Hopkinson, A. C.; Siu, K. W. M. Copper-Mediated Peptide Radical Ions in the Gas Phase. J. Phys. Chem. B 2004, 108, 11170-11181.

10. Barlow, C. K.; McFadyen, W. D.; O'Hair, R. A. J. Formation of Cationic Peptide Radicals by Gas-Phase Redox Reactions with Trivalent Chromium, Manganese, Iron, and Cobalt Complexes. J. Am. Chem. Soc. 2005, $127,6109-6115$

11. Laskin, J.; Yang, Z. B.; Lam, C.; Chu, I. K. Charge-Remote Fragmentation of Odd-Electron Peptide Ions. Anal. Chem. 2007, 79, 6607-6614

12. Sun, Q. Y.; Nelson, H.; Ly, T.; Stoltz, B. M.; Julian, R. R. Side-Chain Chemistry Mediates Backbone Fragmentation in Hydrogen Deficient Peptide Radicals. J. Proteome Res. 2009, 8, 958-966.

13. Ly, T.; Yin, S.; Loo, J. A.; Julian, R. R. Electron-Induced Dissociation of Protonated Peptides Yields Backbone Fragmentation Consistent with a Hydrogen-Deficient Radical. Rapid Commun. Mass Spectrom. 2009, 23, 2099-2101.

14. Lioe, H.; O'Hair, R. A. J. Comparison of Collision-Induced Dissociation and Electron-Induced Dissociation of Singly Protonated Aromatic
Amino Acids, Cystine, and Related Simple Peptides Using a Hybrid Linear Ion Trap-FT-ICR Mass Spectrometer. Anal. Bioanal. Chem. 2007, 389, 1429-1437.

15. Budnik, B. A.; Haselmann, K. F.; Elkin, Y. N.; Gorbach, V. I.; Zubarev R. A. Applications of Electron-Ion Dissociation Reactions for Analysis of Polycationic Chitooligosaccharides in Fourier Transform Mass Spectrometry. Anal. Chem. 2003, 75, 5994-6001.

16. Zubarev, R. A.; Kelleher, N. L.; McLafferty, F. W. Electron Capture Dissociation of Multiply Charged Protein Cations. A Nonergodic Process. J. Am. Chem. Soc. 1998, 120, 3265-3266.

17. Zubarev, R. A.; Haselmann, K. F.; Budnik, B.; Kjeldsen, F.; Jensen, F. Towards an Understanding of the Mechanism of Electron-Capture Dissociation: A Historical Perspective and Modern Ideas. Eur. J. Mass Spectrom. 2002, 8, 337-349.

18. Syrstad, E. A.; Turecek, F. Toward a General Mechanism of Electron Capture Dissociation. J. Am. Soc. Mass Spectrom. 2005, 16, 208-224.

19. Syka, J. E. P.; Coon, J. J.; Schroeder, M. J.; Shabanowitz, J.; Hunt, D. F. Peptide and Protein Sequence Analysis by Electron Transfer Dissociation Mass Spectrometry. Proc. Natl. Acad. Sci. U.S.A. 2004, 101, 9528 9533.

20. Mikesh, L. M.; Ueberheide, B.; Chi, A.; Coon, J. J.; Syka, J. E. P. Shabanowitz, J.; Hunt, D. F. The Utility of ETD Mass Spectrometry in Proteomic Analysis. BBA-Prot. Proteom. 2006, 1764, 1811-1822.

21. Coon, J. J.; Shabanowitz, J.; Hunt, D. F.; Syka, J. E. P. Electron Transfer Dissociation of Peptide Anions. J. Am. Soc. Mass Spectrom. 2005, 16 $880-882$.

22. Laskin, J.; Futrell, J. H.; Chu, I. K. Is Dissociation of Peptide Radical Cations an Ergodic Process? J. Am. Chem. Soc. 2007, 129, 9598-9599.

23. Zhang, L.; Reilly, J. P. Radical-Driven Dissociation of Odd-Electron Peptide Radical Ions Produced in $157 \mathrm{~nm}$ Photodissociation. J. Am. Soc. Mass Spectrom. 2009, 20, 1378-1390.

24. O'Connor, P. B.; Lin, C.; Cournoyer, J. J.; Pittman, J. L.; Belyayev, M. Budnik, B. A. Long-Lived Electron Capture Dissociation Product Ions Experience Radical Migration Via Hydrogen Abstraction. J. Am. Soc. Mass Spectrom. 2006, 17, 576-585.

25. Lin, C.; O'Connor, P. B.; Cournoyer, J. J. Use of a Double Resonance Electron Capture Dissociation Experiment to Probe Fragment Intermediate Lifetimes. J. Am. Soc. Mass Spectrom. 2006, 17, 1605-1615.

26. Cooper, H. J.; Hudgins, R. R.; Hakansson, K.; Marshall, A. G. Characterization of Amino Acid Side-Chain losses in Electron Capture Dissociation. J. Am. Soc. Mass Spectrom. 2002, 13, 241-249.

27. Cooper, H. J.; Hudgins, R. R.; Hakansson, K.; Marshall, A. G. Secondary Fragmentation of Linear Peptides in Electron Capture Dissociation. Int. J. Mass Spectrom. 2003, 228, 723-728.

28. Fung, Y. M. E.; Chan, T. W. D. Experimental and Theoretical Investigations of the Loss of Amino Acid Side Chains in Electron Capture Dissociation of Model Peptides. J. Am. Soc. Mass Spectrom. 2005, 16, 1523-1535.

29. Savitski, M. M.; Nielsen, M. L.; Zubarev, R. A. Side-Chain Losses in Electron Capture Dissociation to Improve Peptide Identification. Anal. Chem. 2007, 79, 2296-2302.

30. Falth, M.; Savitski, M. M.; Nielsen, M. L.; Kjeldsen, F.; Andren, P. E.; Zubarev, R. A. Analytical Utility of Small Neutral Losses from Reduced Species in Electron Capture Dissociation Studied Using SwedECD Database. Anal. Chem. 2008, 80, 8089-8094.

31. Kjeldsen, F.; Zubarev, R. Secondary Losses Via $\gamma$-Lactam Formation in Hot Electron Capture Dissociation: A Missing Link to Complete De Novo Sequencing of Proteins? J. Am. Chem. Soc. 2003, 125, 6628-6629.

32. Haselmann, K. F.; Budnik, B. A.; Kjeldsen, F.; Polfer, N. C.; Zubarev, R. A. Can the (M--X) Region in Electron Capture Dissociation Provide Reliable Information on Amino Acid Composition of Polypeptides? Eur. J. Mass Spectrom. 2002, 8, 461-469.

33. Cooper, H. J.; Hakansson, K.; Marshall, A. G.; Hudgins, R. R.; Haselmann, K. F.; Kjeldsen, F.; Budnik, B. A.; Polfer, N. C.; Zubarev, R. A. Letter: The Diagnostic Value of Amino Acid Side-Chain Losses in Electron Capture Dissociation of Polypeptides. Comment on: "Can the (M--X) Region in Electron Capture Dissociation Provide Reliable Information on Amino Acid Composition of Polypeptides?" Eur. J. Mass Spectrom. 2002, 8, 461-469. Eur. J. Mass Spectrom. 2003, 9, 221-222.

34. Cheng, C.; Gross, M. L. Applications and Mechanisms of ChargeRemote Fragmentation. Mass Spectrom. Rev. 2000, 19, 398-420.

35. Gross, M. L. Charge-Remote Fragmentation: An Account of Research on Mechanisms and Applications. Int. J. Mass Spectrom. 2000, 200, 611-624.

36. Jensen, N. J.; Tomer, K. B.; Gross, M. L. Gas-Phase Ion Decompositions Occurring Remote to a Charge Site. J. Am. Chem. Soc. 1985, 107, 1863-1868.

37. Adams, J.; Gross, M. L. Energy Requirements for Remote Charge Site Ion Decompositions and Structural Information from Collisional Activation of Alkali-Metal Cationized Fatty Alcohols. J. Am. Chem. Soc. 1986, 108, 6915-6921.

38. Adams, J.; Gross, M. L. Charge-Remote Fragmentations of Closed-Shell Ions-a Thermolytic Analogy. J. Am. Chem. Soc. 1989, 111, 435-440.

39. Gross, M. L. Charge-Remote Fragmentations-Method, Mechanism, and Applications. Int. J. Mass Spectrom. Ion Process 1992, 118, 137-165.

40. Han, H. L.; Xia, Y.; McLuckey, S. A. Ion Trap Collisional Activation of $\mathrm{c}$ and $\mathrm{z}$. Ions Formed Via Gas-Phase Ion/Ion Electron Transfer Dissociation. J. Proteome Res. 2007, 6, 3062-3069.

41. Leymarie, N.; Costello, C. E.; O'Connor, P. B. Electron Capture Dissociation Initiates a Free Radical Reaction Cascade. J. Am. Chem. Soc. 2003, $125,8949-8958$. 
42. Jebanathirajah, J. A.; Pittman, J. L.; Thomson, B. A.; Budnik, B. A.; Kaur, P.; Rape, M.; Kirschner, M.; Costello, C. E.; O'Connor, P. B. Characterization of a New qQq-FTICR Mass Spectrometer for Post-Translational Modification Analysis and Top-Down Tandem Mass Spectrometry of Whole Proteins. J. Am. Soc. Mass Spectrom. 2005, 16, 1985-1999.

43. O'Connor, P. B.; Pittman, J. L.; Thomson, B. A.; Budnik, B. A. Cournoyer, J. C.; Jebanathirajah, J.; Lin, C.; Moyer, S.; Zhao, C. A New Hybrid Electrospray Fourier Transform Mass Spectrometer: Design and Performance Characteristics. Rapid Commun. Mass Spectrom. 2006, 20, 259-266.

44. Swaney, D. L.; McAlister, G. C.; Wirtala, M.; Schwartz, J. C.; Syka, J. E. P.; Coon, J. J. Supplemental Activation Method for High-Efficiency Electron-Transfer Dissociation of Doubly Protonated Peptide Precursors. Anal. Chem. 2007, 79, 477-485.

45. Cooper, H. J. Investigation of the Presence of b Ions in Electron Capture Dissociation Mass Spectra. J. Am. Soc. Mass Spectrom. 2005, 16, 1932-1940.

46. Liu, H. C. Hakansson, K. Abundant b-Type Ions Produced in Electron Capture Dissociation of Peptides Without Basic Amino Acid Residues. J. Am. Soc. Mass Spectrom. 2007, 18, 2007-2013.

47. Li, X.; Cournoyer, J. J.; Lin, C.; O'Connor, P. B. The Effect of Fixed Charge Modifications on Electron Capture Dissociation. J. Am. Soc. Mass Spectrom. 2008, 19, 1514-1526.

48. Belyayev, M. A.; Cournoyer, J. J.; Lin, C.; O'Connor, P. B. The Effect of Radical Trap Moieties on Electron Capture Dissociation Spectra of Substance P. J. Am. Soc. Mass Spectrom. 2006, 17, 1428-1436.

49. Kjeldsen, F.; Haselmann, K. F.; Budnik, B. A.; Jensen, F.; Zubarev, R. A Dissociative Capture of Hot (3-13 eV) Electrons by Polypeptide Polycations: An Efficient Process Accompanied by Secondary Fragmentation. Chem. Phys. Lett. 2002, 356, 201-206.
50. Cournoyer, J. J.; Pittman, J. L.; Ivleva, V. B.; Fallows, E.; Waskell, L. Costello, C. E.; O'Connor, P. B. Deamidation: Differentiation of Asparty from Isoaspartyl Products in Peptides by Electron Capture Dissociation. Protein Sci. 2005, 14, 452-463.

51. Cournoyer, J. J.; Lin, C.; O'Connor, P. B. Detecting Deamidation Products in Proteins by Electron Capture Dissociation. Anal. Chem. 2006, $78,1264-1271$

52. Cournoyer, J. J.; Lin, C.; Bowman, M. J.; O'Connor, P. B. Quantitating the Relative Abundance of Isoaspartyl Residues in Deamidated Proteins by Electron Capture Dissociation. J. Am. Soc. Mass Spectrom. 2007, 18, $48-56$.

53. Li, X.; Cournoyer, J. J.; Lin, C.; O'Connor, P. B. Use of O-18 Labels to Monitor Deamidation During Protein and Peptide Sample Processing. J. Am. Soc. Mass Spectrom. 2008, 19, 855-864.

54. O'Connor, P. B.; Cournoyer, J. J.; Pitteri, S. J.; Chrisman, P. A.; McLuckey, S. A. Differentiation of Aspartic and Isoaspartic Acids Using Electron Transfer Dissociation. J. Am. Soc. Mass Spectrom. 2006, 17, 15-19.

55. Kjeldsen, F.; Haselmann, K. F.; Sorensen, E. S.; Zubarev, R. A. Distinguishing of Ile/Leu Amino Acid Residues in the PP3 Protein by (Hot) Electron Capture Dissociation in Fourier Transform Ion Cyclotron Resonance Mass Spectrometry. Anal. Chem. 2003, 75, 1267-1274.

56. Savitski, M. M.; Kjeldsen, F.; Nielsen, M. L.; Zubarev, R. A. Hydrogen Rearrangement to and from Radical z Fragments in Electron Capture Dissociation of Peptides. J. Am. Soc. Mass Spectrom. 2007, 18, 113-120.

57. Lin, C.; Cournoyer, J. C.; O'Connor, P. B. Probing the Gas Phase Folding Kinetics of Peptide Ions by IR Activated DR-ECD. J. Am. Soc. Mass Spectrom. 2008, 19, 780-789. 